\title{
Preparation of Silk Fibroin Microspheres and Its Cytocompatibility
}

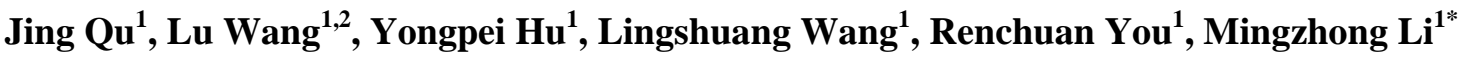 \\ ${ }^{1}$ National Engineering Laboratory for Modern Silk, College of Textile and Clothing Engineering, Soochow University, Suzhou, \\ China; ${ }^{2}$ Institute of Coal Chemistry, Chinese Academy of Sciences, Taiyuan, China. \\ Email: ${ }^{*}$ mzli@suda.edu.cn
}

Received October $15^{\text {th }}, 2012$; revised November $29^{\text {th }}, 2012$; accepted December $13^{\text {th }}, 2012$

\begin{abstract}
The goal of this proof-of-concept study was the fabrication of porous silk fibroin (SF) microspheres which could be used as cell culture carriers under very mild processing conditions. The SF solution was differentiated into droplets which were induced by a syringe needle in the high-voltage electrostatic field. They were collected and frozen in liquid nitrogen and water in droplets formed ice crystals which sublimated during lyophilization and a great quantity of micropores shaped in SF microspheres. Finally, the microspheres were treated in ethanol so as to transfer the molecular conformation into $\beta$-sheet and then they were insoluble in water. SF particles were spherical in shape with diameters in the range of $208.4 \mu \mathrm{m}$ to $727.3 \mu \mathrm{m}$, while the pore size on the surface altered from $0.3 \mu \mathrm{m}$ to $10.7 \mu \mathrm{m}$. In vitro, the performances of SF microspheres were assessed by culturing L-929 fibroblasts cells. Cells were observed to be tightly adhered and fully extended; also a large number of connections were established between cells. After 5-day culture, it could be observed under a confocal laser scanning microscope that the porous microenvironment offered by SF particles accelerated proliferation of cells significantly. Furthermore, porous SF particles with smaller diameters (200 - 300 $\mu \mathrm{m})$ might promote cell growth better. These new porous SF microspheres hold a great potential for cell culture carriers and issue engineering scaffolds.
\end{abstract}

Keywords: Silk Fibroin; Microspheres; High-Voltage Electrostatic Field; Cytocompatibility

\section{Introduction}

Amplification of seed cells is the basis of tissue engineering, while microcarrier technology has realized the extensive culture of animal cells. The higher specific surface area of microspheres could provide adequate adherent place for cells so as to be conducive to cell adhesion and proliferation. The current research about microcarriers focuses on polysaccharides, including cellulose, chitosan, hyaluronic acid, alginate, dextran and starch, as well as on proteins such as collagen, gelatin, elastin, albumin and silk fibroin $[1,2]$.

Silk fibroin is a natural, fibrous protein with excellent biocompatibility and mechanical property $[3,4]$. SF materials can support the attachment, proliferation, and differentiation of primary cells and cell lines [5-7], and is easily prepared as films [8], porous scaffolds [9], gels [10], and tubular scaffolds [11]. The impressive cytocompatibility of SF materials make silk a popular starting material for tissue engineering scaffolds used in skin, bone, blood vessel, ligament, and nerve tissue regeneration [12-14].

\footnotetext{
*Corresponding author.
}

The preparation methods of SF microspheres mainly include protein denaturation method, emulsificationcuring method, spray-drying method, template method, and high-voltage electrostatic technology. Desolvation technique was implemented for the preparation SF particles using dimethyl sulfoxide (DMSO) as desolvating agent [15], besides, SF particles of controllable sizes (500 $\mathrm{nm}$ to $2 \mu \mathrm{m}$ ) also could be obtained in an all-aqueous process by salting out with potassium phosphate [16]. Using the simple water-in-oil emulsion solvent diffusion method has been described to prepare genipin-crosslinked SF microspheres [17], while spray-drying method for fabricating spherical SF particles with average size 2 to $10 \mu \mathrm{m}$ has been investigated in recent years [18]. Apart from these, Wang et al. [19] developed a method to prepare SF microspheres by using lipid vesicles as templates, and then the lipid was subsequently removed by methanol or sodium chloride treatments, resulting in silk microspheres consisting of $\beta$-sheet structure and about $2 \mu \mathrm{m}$ in diameter. Wenk et al. [20] fabricated SF spheres by using the laminar jet break-up of aqueous SF solution, which was induced by a nozzle vibrating at controlled frequency and amplitude. Both treatments, 
either methanol or exposure to water vapor, resulted in an increase in $\beta$-sheet content.

SF materials with porous structure on surface are more helpful for cellular pseudopods extension, intercellular signal transmission, and extracellular matrix deposition [21]. On the other hand, if the chemical reagents such as acetone, methanol, DMSO, etc. used in the process of preparation of microcarriers residues; it will undoubtedly have a negative impact on cell proliferation and growth [22-24]. To establish a very mild processing condition, the SF microspheres in this study were prepared by differentiating SF solution into droplets, which were induced by a nozzle under high-voltage electrostatic field. The droplets were collected in liquid nitrogen so that water in which crystallized into icicles. Then the icicles sublimated after lyophilization and a large amount of micropores were produced on the surface and inside the microspheres. In order to make them stable in water, SF particles were exposed to ethanol. Finally, they were freeze-dried again followed steeped into deionized water to remove residual ethanol. The adhesion and growth of murine fibroblast cells L-929 on the surface of SF microspheres with different diameters were emphasized.

\section{Materials and Methods}

\subsection{Fabrication of Silk Fibroin Microspheres}

Silk fibroin aqueous solutions were prepared as previously described [25]. Briefly, $150 \mathrm{~g}$ raw silk fibers (purchased from Zhejiang the Second Silk Co. Ltd, Hangzhou, China) were degummed three times in $5000 \mathrm{ml}$ aqueous solution of $0.02 \mathrm{M}$ sodium carbonate, and then rinsed thoroughly with deionized water. After drying in an oven at $60^{\circ} \mathrm{C}$, the extracted $\mathrm{SF}$ was dissolved in $9.3 \mathrm{M}$ $\mathrm{LiBr}$ solution at $60^{\circ} \mathrm{C}$ for $4 \mathrm{~h}$. A $4.0 \mathrm{wt} \% \mathrm{SF}$ solution obtained after dialysis of 4 days in deionized water followed by filtration was diluted with deionized water to a concentration of $3 \mathrm{wt} \%$.

SF spheres were prepared by using high pressure electrostatic generator (DW-P503-4ACCD, Dongwen High Voltage Power Plant, Tianjin, China) and micro-injection pump (WZS50F2, Zhejiang University Medical Instrument Co., Ltd, Zhejiang, China). A nozzle with diameter of $0.7 \mathrm{~mm}$ was linked with the syringe and the whole were fixed on the pump. The distance between the needle and the collection box was settled $100 \mathrm{~mm}$. The $3 \mathrm{wt} \%$ SF solution in injector was differentiated into droplets under a high-voltage electrostatic field. The produced droplets were continuously collected and frozen in a liquid nitrogen bath (Figure 1). The frozen SF microspheres were freeze-dried in Virtis Genesis 25-LE lyophilizer for $48 \mathrm{~h}$. The dry spheres were treated with a $75 \%(\mathrm{v} / \mathrm{v})$ aqueous ethanol solution at room temperature for $2 \mathrm{~h}$ to induce SF structural transformation. Porous SF

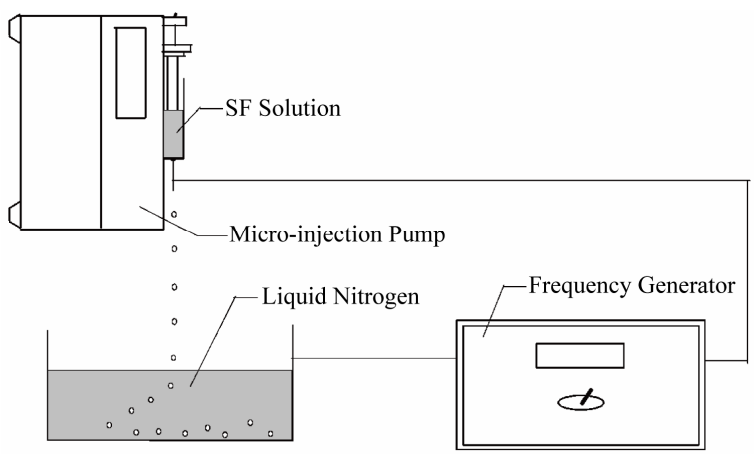

Figure 1. Illustration showing the experimental setup used for the preparation of SF spheres.

microspheres which were insoluble in water could be obtained after lyophilized again followed after steeping into deionized water for 3 days to remove residual ethanol.

\subsection{Morphology and Structure of SF Microspheres}

The surface and cross-section of SF microspheres were examined morphologically by scanning electron microscopy (SEM, Hitachi S-4700, Japan). The particle size of SF spheres was analyzed on the basis of SEM images with the Nano Measurer analysis software (Department of Chemistry, Fudan University, Shanghai, China). For each particle preparation we determined the average of the equivalent circular diameter of a total of 100 spheres.

Untreated and treated with ethanol SF spheres were cut into powder with radii less than $40 \mu \mathrm{m}$, the samples were mixed with $\mathrm{KBr}$ and compressed to $\mathrm{KBr}$ disks. FTIR spectroscopy was performed with a Nicolet 5700 FT-IR (Nicolet Company, USA). The wave number ranged from 400 to $4000 \mathrm{~cm}^{-1}$.

\subsection{Cell Adhesion, Proliferation and Viability Study}

Murine fibroblasts cell line L-929 (Basic Medicine and Life Science Academy of Soochow University, Suzhou, China) was chosen to evaluate the influence of SF spheres with different particle sizes on cell adhesion and proliferation. $3 \mathrm{mg}$ various SF spheres were put in a 24well tissue culture plate (TCP, Corning Inc., USA), and then rinsed with tri-distilled water for 7 days followed by sterilization with $\gamma$-ray irradiation. SF spheres were soaked with serum-containing medium for $30 \mathrm{~min}$ before the fibroblasts were seeded so as to increase cell adhesion. Murine fibroblasts at a density of $1 \times 10^{5}$ cells per well were seeded onto the SF spheres in 24-well plates and blank culture plates for control experiments. The medium used was 90\% Dulbecco's modified Eagle's medium (DMEM), 9.0\% bull serum albumin (BSA), and $1.0 \%$ Streptomgein/Ampicillin (purchased from Sibas 
Biotechnology Co., Ltd., Shanghai, China). The cellseeded SF spheres were incubated at $37^{\circ} \mathrm{C}$ in $5 \% \mathrm{CO}_{2}$ atmosphere, and the medium in the well was replaced with fresh medium every other day. After 5 days in culture on microspheres, cells were fixed with $2.5 \%$ glutaraldehyde and then incubated overnight at $4^{\circ} \mathrm{C}$. The fixed microsphere cultures were washed twice with phosphate-buffered saline (PBS), froze at $-80^{\circ} \mathrm{C}$ for $2 \mathrm{~h}$, and freeze-dried for $36 \mathrm{~h}$. Dry samples were platinumcoated in vacuum and examined by SEM.

The proliferation of cells on SF microspheres was observed by confocal scanning laser microscope (CLSM, TCS-SP2, Leica Company, German). L-929 cells on various SF microspheres and culture plates were labeled with CM-DiI fluorescent dye, then were observed by CLSM when incubated for 1,3 , and 5 days. Cultures on SF particles were selected for cell counting on days 1,3 , 5,7 , and 9 in vitro by cell counting chamber after they were washed twice with PBS and digested for $20 \mathrm{~min}$ with trypsin.

The methyl thiazolyl tetrazolium (MTT) assay was used to measure the cell viability. After 1, 3, 5, 7, and 9 days, $200 \mu \mathrm{l}$ MTT dye solution $(5 \mathrm{mg} / \mathrm{ml}$ in phosphate buffer at $\mathrm{pH}$ 7.4) was added into each well. After $4 \mathrm{~h}$ of incubation at $37^{\circ} \mathrm{C}$ and $5 \% \mathrm{CO}_{2}$, the medium was removed and formazan crystals were solubilized in $\mathrm{HCl}$ Isopropanol overnight. The optical density (OD) of formazan was measured on a Synergy HT (BIO-TEK) microplate reader at $490 \mathrm{~nm}$. Data were presented as means \pm SD. Statistical comparisons were performed using ANOVA, and differences at $\mathrm{P}<0.05$ were considered statistically significant.

\section{Results and Discussion}

\subsection{Morphology of SF Microspheres}

Process parameters included SF solution concentrations, electrostatic voltage, solution flow rate, inner diameter of needle, and collection distance, while electrostatic voltage and solution flow rate had deeper influence on particle size. Four groups of (a), (b), (c), and (d) microspheres with various diameters were obtained by changing electrostatic voltage and solution flow rate (Table 1) in this study.

From Table 1 and Figure 2, the particle size increased significantly as the electrostatic voltage decreased and the flow rate increased. The average diameters of group (a), (b), (c), and (d) spheres were respectively $208.4 \mu \mathrm{m}$, $306.2 \mu \mathrm{m}, 505.7 \mu \mathrm{m}$, and $727.3 \mu \mathrm{m}$.

The SEM images (Figure 3) showed that the SF particle was full of pores on its surface, exhibiting a porous structure, and pore size on surface ranged from 0.3 to $10.7 \mu \mathrm{m}$. These might be explained that during the freezing process, when the temperature of water in SF solu-
Table 1. The processing parameters of electrostatic differentiation method and the average diameter of sf microspheres.

\begin{tabular}{|c|c|c|c|}
\hline \multirow[b]{2}{*}{ Groups } & \multicolumn{2}{|c|}{ Processing Parameters } & \multirow{2}{*}{$\begin{array}{c}\text { Diameter of } S F \\
\text { microspheres } \\
(\mu \mathrm{m})\end{array}$} \\
\hline & $\begin{array}{l}\text { Electrostatic } \\
\text { Voltage }(\mathrm{kV})\end{array}$ & $\begin{array}{c}\text { Flow Rate } \\
(\mathrm{ml} / \mathrm{h})\end{array}$ & \\
\hline (a) & 9 & 0.9 & 208.4 \\
\hline (b) & 9 & 2.0 & 306.2 \\
\hline (c) & 6 & 4.5 & 505.7 \\
\hline (d) & 6 & 6.0 & 727.3 \\
\hline
\end{tabular}

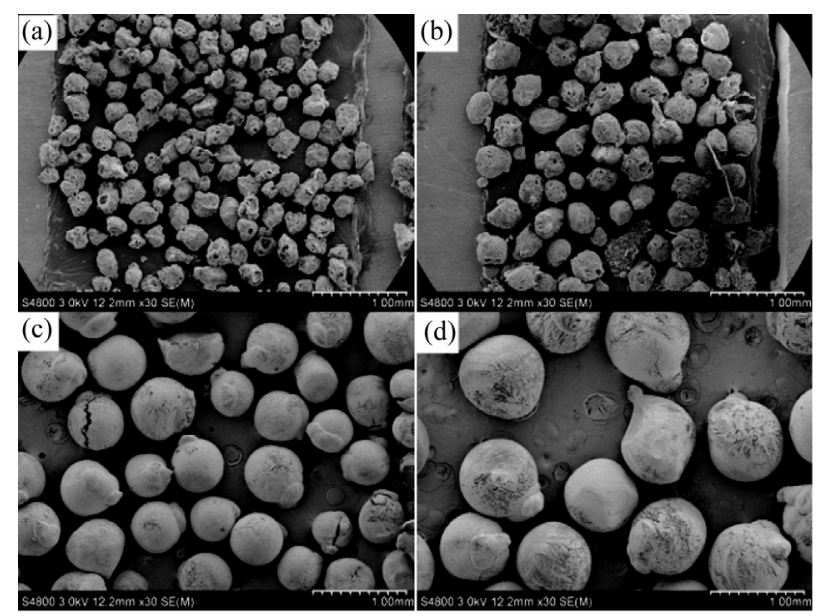

Figure 2. SEM photographs of SF microspheres of groups (a)-(d) in Table 1. Scale bar $=1.0 \mathrm{~mm}$.

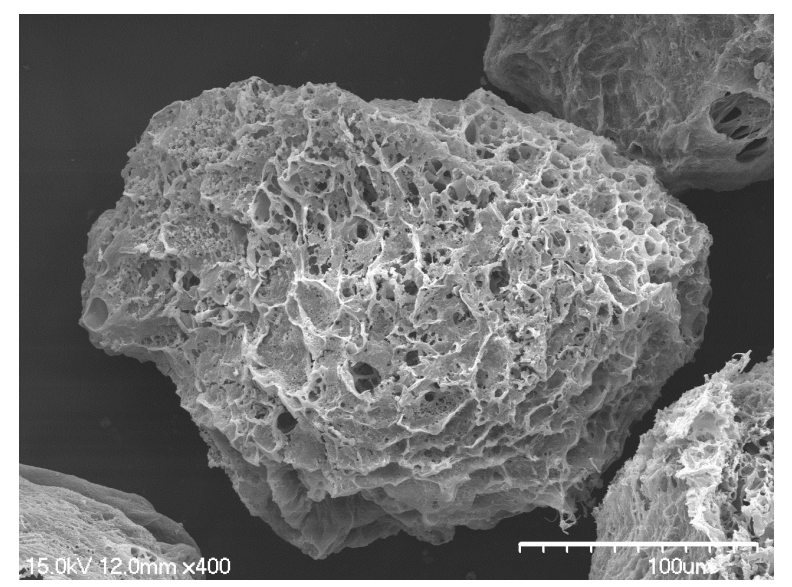

Figure 3. SEM photograph of SF microspheres. Scale bar $=$ $1.0 \mathrm{~mm}$.

tion was below ice point, ice nucleus was emerged due to heat exchange. Because of supercooling, the chemical potential of water in unstable SF solution phase was higher than that of ice nucleus so that ice nucleus grew into large ice particles [26]. SF solution around these ice particles was concentrated accordingly, then the distance between fibroin molecules in random coil shortened, and the chain segments interfingered to form continuous fib- 
roin solution phase. SF microspheres with porous structure were gained after those ice crystals which were dispersed in fibroin phase sublimated. Pores around the interior of microspheres were larger than those in center so that the ambient structure was loose while structure in center was compact respectively. During the freezing process, the wall of particle touched liquid nitrogen first, resulting that temperature in center was higher than it of the wall and subsequently ice crystals grew to center longitudinally. The water in SF solution was assembled into larger ice particles with the function of the crystals in the wall of SF spheres. Simultaneously, fibroin molecules closed further to each other, then such structure of loose around and compact in center formed after ice particles sublimated.

\subsection{Condensed Structure of SF Microspheres}

FTIR spectra (Figure 4) indicated that untreated particles (Curve a) showed absorption bands at $1651 \mathrm{~cm}^{-1}$ (amide I), $1536 \mathrm{~cm}^{-1}$ (amide II) and $1235 \mathrm{~cm}^{-1}$ (amide III), which attributed to random coil and silk I structure. However, the amide I, amide II and amide III bands shifted to $1630 \mathrm{~cm}^{-1}, 1520 \mathrm{~cm}^{-1}$ and $1232 \mathrm{~cm}^{-1}$ respectively after being treated by ethanol, indicating that the SF conformation mainly exhibited silk II structure. When SF microspheres were in contact with ethanol aqueous solution, the water could infiltrate between SF macromolecules and its interior, naturally silk fibroin swelled up. On account of the osmosis of abundant ethanol and water, they strove for water with fibroin, and lowered the permittivity around SF macromolecules in the meantime. Fibroin macromolecular chain segments were forced to rearrange to form thermodynamically stable $\beta$-sheet structure, then the water-insoluble SF microspheres were obtained.

\subsection{Cell Growth on the Surface of SF Microspheres}

L-929 cells were seeded on SF spheres of groups (a), (b), (c), and (d) at a density of $1 \times 10^{5}$ cells per well in $1.0 \mathrm{ml}$ of growth medium and allowed to attach for $4 \mathrm{~h}$ at $37^{\circ} \mathrm{C}$ with $5 \% \mathrm{CO}_{2}$ atmosphere in an incubator.

The SEM observation of L-929 cells cultured on SF particles with different sizes showed that cells on spheres were of high density and represented normal morphology (Figure 5). Besides, cells adhered on SF spheres tightly and evenly, pseudopods of cells linked to each other to form cell-cell networks which were highly helpful to intercellular signal transmission. On top of that, a mass of extracellular matrix was precipitated in pores of SF particles. All of these indicated that porous SF microspheres could support cellular adhesion, growth and proliferation.

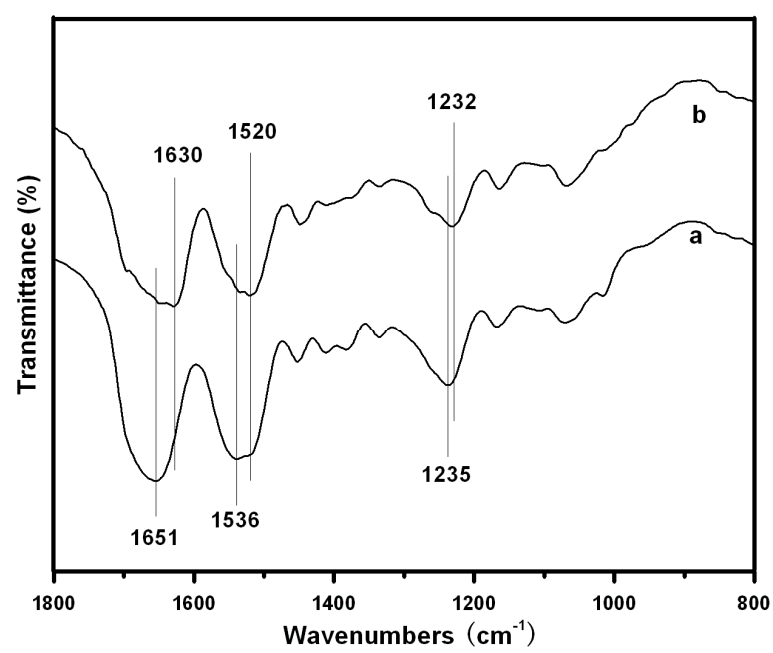

Figure 4. FTIR spectra of (a) untreated (b) ethanol treated SF microspheres.
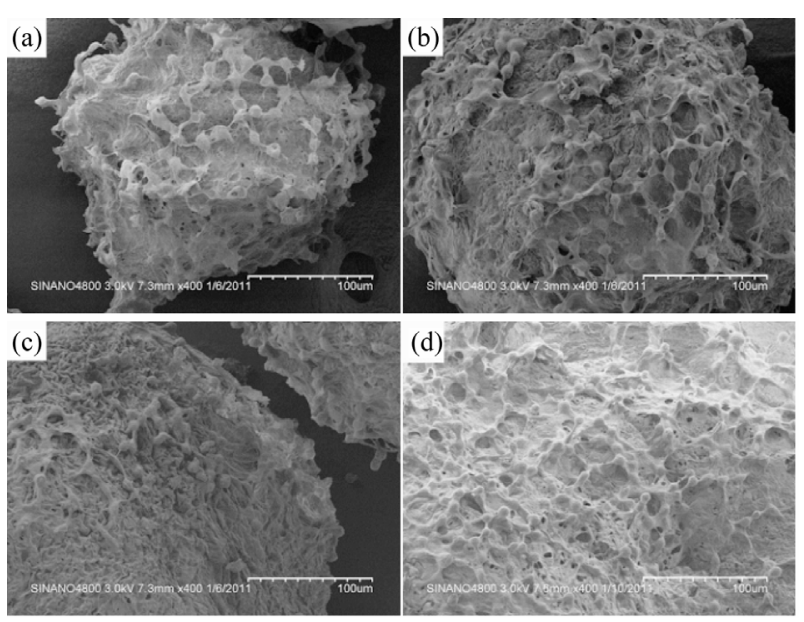

Figure 5. SEM images of L-929 cells on SF microspheres of groups (a)-(d) after 5 days in culture.

Growth of L-929 cells on SF spheres was examined by CLSM. SF particles appeared black while CM-labeled cells presented red under CLSM; the single red point was clear which revealed that cells were labeled well (Figure 6). Fibroblasts could adhere on various SF spheres, indicating that cells were of good compatibility with SF materials. As the elongation of days in culture, the fluorescence intensity enhanced, showing that the number of cells increased accordingly. These also specified that SF microspheres could be conducive to the growth and proliferation of L-929 cells.

In the early days of cell culture $(1-5 d)$, cellular adhesion rate of SF spheres was lower than that of cell culture plates due to cell inoculation (Figure 7). However, after 7 days in culture, the number of cells on particles increased significantly which could be explained that the larger specific surface area of SF spheres offered adequate space for cells. The existence of abundant pores 

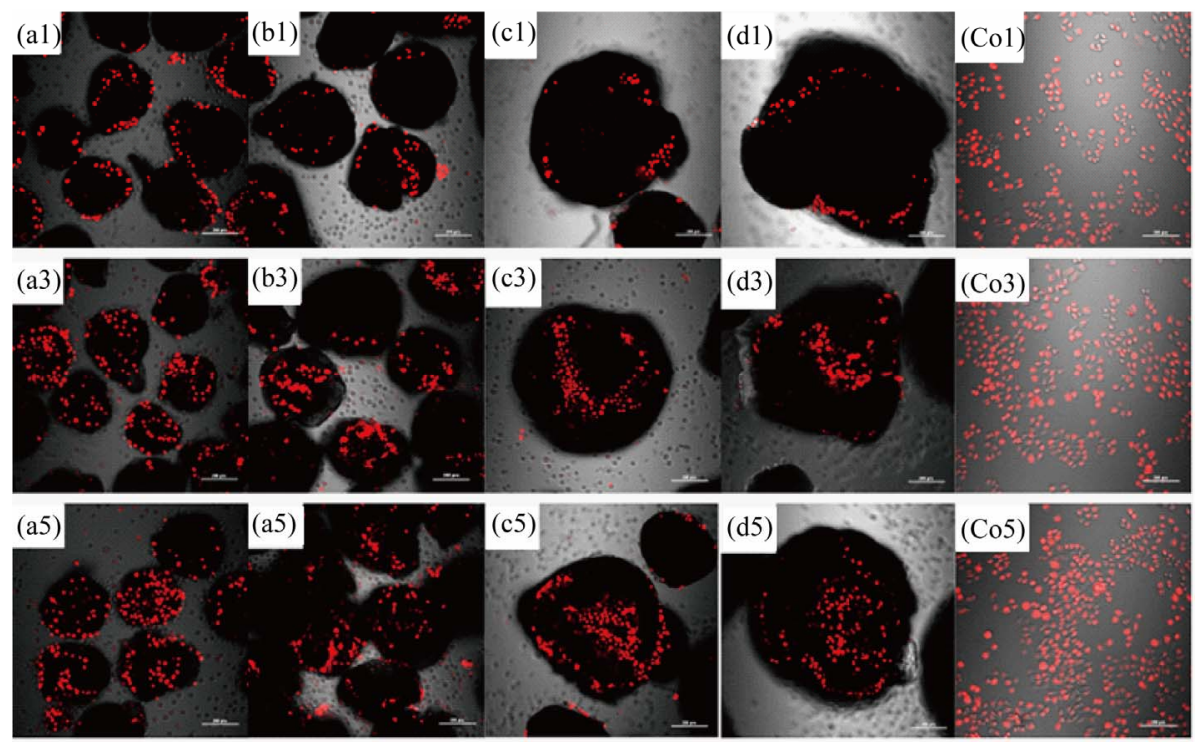

Figure 6. CLSM images of L-929 cells cultured on SF microspheres of groups (a)-(d) for 5 days.

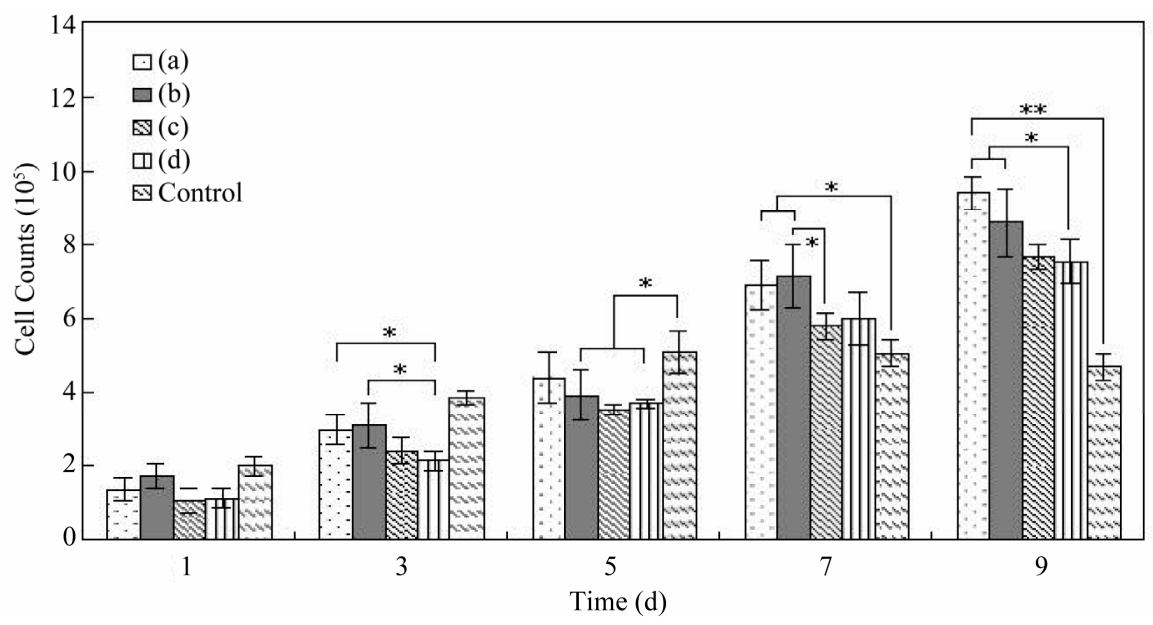

Figure 7. L-929 Cells counts on SF microspheres of groups (a)-(d) $\left({ }^{*} \mathrm{P}<0.05,{ }^{* *} \mathrm{P}<0.01\right)$.

was also favorable for cellular pseudopods extension, intercellular and cell-surroundings signal transmission, and extracellular matrix deposition. During culture process, cells on various SF particles manifested different growth state. As time increased, the number of cells on smaller SF particles $(208.4 \mu \mathrm{m}, 306.2 \mu \mathrm{m})$ was obviously more than that on larger ones $(505.7 \mu \mathrm{m}, 727.3 \mu \mathrm{m})$ owing to the larger specific surface area and more pores of smaller spheres.

The quantity of viable L-929 cells on SF microspheres with various sizes was estimated using the MTT assay (Figure 8). After cultivation for 3 and 5 days, the number of viable cells on different particles increased rapidly as evidenced by an increase absorbance compared with that on day 1 , and the $\mathrm{OD}_{490}$ of group $\mathrm{A}$ and $\mathrm{B}$ were higher than the control. By day 7, microspheres showed obvious superiority judged from the large discrepancy of the particles and the culture plates. These results suggested that SF microspheres provided more space for cell growth and proliferation, and spheres with smaller size were more contributable to accelerate the proliferation rate of cells for their larger specific surface area.

\section{Conclusion}

The fabrication of SF microspheres with controllable sizes combining high-voltage electrostatic field differentiating and freeze-drying technique was described, and the structure of SF particles was induced by the ethanol treatment. Murine fibroblasts L-929 could adhere tightly on the surface of porous SF microspheres with diverse diameters as the larger specific surface area of spheres offered adequate adherent place for cellular vast proliferation. The existence of plentiful pores further supplied 


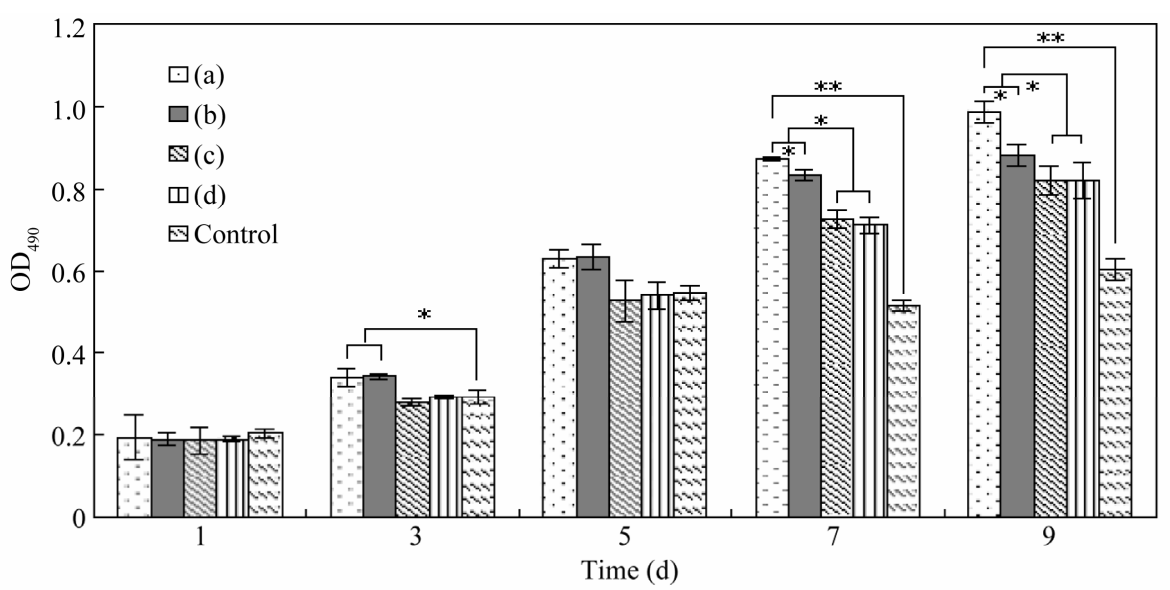

Figure 8. MTT assays of L-929 cell viability on SF particles of groups (a)-(d) $\left({ }^{*} \mathbf{P}<0.05,{ }^{* *} \mathbf{P}<0.01\right)$.

better microenvironment for cellular pseudopods extension, and cell-external signal transmission. Particles of smaller size were more conducive to cellular adhesion and proliferation. Therefore, such porous SF microspheres have a potential application as cell culture carriers.

\section{Acknowledgements}

This work was supported by the National Nature Science Foundation of China (30970714), the College Natural Science Research Project of Jiangsu Province (12KJA430003), the Key Program in Medical Science Research of Military (No.BWS11C061) and the Priority Academic Program Development of Jiangsu Higher Education Institutions.

\section{REFERENCES}

[1] J. F. Mano, G. A. Silva, H. S. Azevedo, P. B. Malafaya, R. A. Sousa, S. S. Silva, L. F. Boesel, J. M. Oliveira, T. C. Santos, A. P. Marques, N. M. Neves and R. L. Reis, "Natural Origin Biodegradable Systems in Tissue Engineering and Regenerative Medicine: Present Status and Some Moving Trends," Journal of The Royal Society Interface, Vol. 4, No. 17, 2007, pp. 999-1030. doi:10.1098/rsif.2007.0220

[2] P. B. Malafaya, G. A. Silva and R. L. Reis, "NaturalOrigin Polymers as Carriers and Scaffolds for Biomolecules and Cell Delivery in Tissue Engineering Applications," Advanced Drug Delivery, Vol. 4-5, No. 59, 2007, pp. 207-233. doi:org/10.1016/j.addr.2007.03.012

[3] G. H. Altman, F. Diaz, C. Jakuba, T. Calabro, R. L. Horan, J. S. Chen, H. Lu, J. Richmond and D. L. Kaplan, "Silk-Based Biomaterials," Biomaterials, Vol. 24, No. 3, 2003, pp. 401-416. doi:org/10.1016/S0142-9612(02)00353-8

[4] C. Vepari and D. L. Kaplan, "Silk as a Biomaterial," Process in Polymer Science, Vol. 32, No. 8-9, 2007, pp. 991-1007. doi:org/10.1016/j.progpolymsci.2007.05.013
[5] N. Minoura, S. Aiba, Y. Gotoh, M. Tsukada and Y. Imai, "Attachment and Growth of Cultured Fibroblast Cells on Silk Protein Matrices," Journal of Biomedical Materials Research, Vol. 29, No. 10, 1995, pp. 1215-1221. doi: $10.1002 / \mathrm{jbm} .820291008$

[6] R. E. Unger, K. Peters, M. Wolf, A. Motta, C. Migliaresi and C. J. Kirkpatrick, "Endothelialization of a Non-Woven Silk Fibroin Net for Use in Tissue Engineering: Growth and Gene Regulation of Human Endothelial Cells," Biomaterials, Vol. 25, No. 21, 2004, pp. 5137 5146. doi:org/10.1016/j.biomaterials.2003.12.040

[7] X. Y. Luan, Y. Wang, X. Duan, Q. Y. Duan, M. Z. Li, S. Z. Lu, H. X. Zhang and X. G. Zhang, "Attachment and Growth of Human Bone Marrow Derived Mesenchymal Stem Cells on Regenerated Antheraea pernyi Silk Fibroin Films," Biomedical Materials, Vol. 1, No. 4, 2006, pp. 181-187. doi:10.1088/1748-6041/1/4/001

[8] Q. Lu, X. Hu, X. Q. Wang, J. A. Kluge, S. Z. Lu, P. Cebe and D. L. Kaplan, "Water-Insoluble Silk Films with Silk I Structure," Acta Biomaterialia, Vol. 6, No. 4, 2010, pp. 1380-1387. doi:org/10.1016/j.actbio.2009.10.041

[9] M. Z. Li, M. Ogiso and N. Minoura, "Enzymatic Degradation Behavior of Porous Silk Fibroin Sheets," Biomaterials, Vol. 24, No. 2, 2003, pp. 357-365. doi:org/10.1016/S0142-9612(02)00326-5

[10] Q. Lu, Y. L. Huang, M. Z. Li, B. Q. Zuo, S. Z. Lu, J. N. Wang, H. Zhu and D. L. Kaplan, "Silk Fibroin Electrogelation Mechanisms," Acta Biomaterialia, Vol. 7, No. 6, 2011, pp. 2394-2400. doi:org/10.1016/j.actbio.2011.02.032

[11] J. Zhou, C. B. Cao and X. L. Ma, "A Novel Three-Dimensional Tubular Scaffold Prepared from Silk Fibroin by Electrospinning," International Journal of Biological Macromolecules, Vol. 45, No. 5, 2009, pp. 504-510. doi:org/10.1016/j.ijbiomac.2009.09.006

[12] L. Meinel, R. Fajardo, S. Hofmann, R. Langer, J. Chen, B. Snyder, V. N. Cordana and D. Kaplan, "Silk Implants for the Healing of Critical Size Bone Defects," Bone, Vol. 37, No. 5, 2005, pp. 688-698. doi:org/10.1016/j.bone.2005.06.010

[13] L. Soffer, X. Q. Wang, X. H. Zhang, J. Kluge, L. Dorf- 
mann, D. L. Kaplan and G. Leisk, "Silk-Based Electrospun Tubular Scaffolds for Tissue-Engineered Vascular Grafts," Journal of Biomaterials and Science, Polymer Edition, Vol. 19, No. 5, 2008, pp. 653-664. doi:10.1163/156856208784089607

[14] L. Uebersax, H. P. Merkle and L. Meinel, "Insulin-Like Growth Factor I Releasing Silk Fibroin Scaffolds Induce Chondrogenic Differentiation of Human Mesenchymal Stem Cells," Journal of Controlled Release, Vol. 127, No. 1, 2008, pp. 12-21. doi:org/10.1016/j.jconrel.2007.11.006

[15] J. Kundu, Y. Chung, Y. H. Kim, G. Tae and S. C. Kundu, "Silk Fibroin Nanoparticles for Cellular Uptake and Control Release," International Journal of Pharmaceutics, Vol. 388, No. 1-2, 2010, pp. 242-250. doi:org/10.1016/j.ijpharm.2009.12.052

[16] S. Lammel, X. Hu, S. H. Park and L. K. David, "Controlling Silk fibroin Particle Features for Drug Delivery," Biomaterials, Vol. 31, No. 16, 2010, pp. 4583-4591. doi:org/10.1016/j.biomaterials.2010.02.024

[17] T. Imsombut, P. Srihanam, P. Srihanam and Y. Baimark, "Genipin-Cross-Linked Silk Fibroin Microspheres Prepared by the Simple Water-in-Oil Emulsion Solvent Diffusion Method," Powder Technology, Vol. 203, No. 3, 2010, pp. 603-608. doi:org/10.1016/j.powtec.2010.06.027

[18] J. H. Yeo, K. G. Lee, Y. W. Lee and S. Y. Kim, "Simple Preparation and Characteristics of Silk Fibroin Microsphere," European Polymer Journal, Vol. 39, No. 6, 2003, pp. 1195-1199. doi:org/10.1016/S0014-3057(02)00359-2

[19] X. Q. Wang, E. Wenk and A. Matsumoto, "Silk Microspheres for Encapsulation and Controlled Release," Journal of Controlled Release, Vol. 117, No. 3, 2007, pp. 360-370. doi:org/10.1016/j.jconrel.2006.11.021

[20] E. Wenk, A. J. Wandrey, H. P. Merkle and L. Meinel, "Silk Fibroin Spheres as a Platform for Controlled Drug
Delivery," Journal of Controlled Release, Vol. 132, No. 1, 2008, pp. 26-34. doi:org/10.1016/j.jconrel.2008.08.005

[21] J. Zeltinger, J. K. Sherwood, D. A. Graham, R. Mueller and L. G. Griffith, "Effect of Pore Size and Void Fraction on Cellular Adhesion, Proliferation, and Matrix Deposition," Tissue Engineering, Vol. 7, No. 5, 2001, pp. 557572. doi:10.1089/107632701753213183

[22] J. F. Sola, F. Fatjo, E. Sacanella, R. Estruch, X. Bosch, A. U. Marquez and J. M. Nicolas, "Evidence of Apoptosis in Alcoholic Cardiomyopathy," Human Pathology, Vol. 37, No. 8, 2006, pp. 1100-1110. doi:10.1016/j.humpath.2006.03.022

[23] U. H. Jin, D. Y. Lee, D. S. Kim, I. S. Lee and C. H. Kim, "Induction of Mitochondria-Mediated Apoptosis by Methanol Fraction of Ulmus davidiana Planch (Ulmaceae) in U87 Glioblastoma Cells," Environmental Toxicology and Pharmacology, Vol. 22, No. 2, 2006, pp. 136-141. doi:org/10.1016/j.etap.2006.01.005

[24] Y. L. Cheng, W. L. Chang, S. C. Lee, Y. G. Liu, C. J. Chen, S. Z. Lin, N. M. Tsai, D. S. Yu, C. Y. Yen and H. J. Harn, "Acetone Extract of Angelica sinensis Inhibits Proliferation of Human Cancer Cells via Inducing Cell Cycle Arrest and Apoptosis," Life Sciences, Vol. 75, No. 13, 2004, pp. 1579-1594. doi:org/10.1016/j.lfs.2004.03.009

[25] S. Sofia, M. B. McCarthy, G. Gronowicz and D. L. Kaplan, "Functionalized Silk-Based Biomaterials for Bone Formation," Journal of Biomedical Materials Research, Vol. 54, No. 1, 2001, pp. 139-148. doi:10.1002/1097-4636(200101)54:1<139::AID-JBM17> 3.0.CO;2-7

[26] Y. Tamada, "New Process to Form a Silk Fibroin Porous 3-D Structure," Biomacromolecules, Vol. 6 No. 6, 2005 , pp. 3100-3106. doi:10.1021/bm050431f 